\title{
A nano-sensor based on screen printed electrode (SPE) for electro-chemical detection of vitamin B9
}

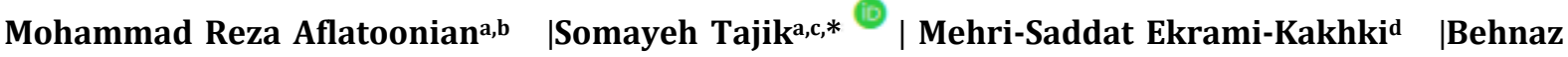 \\ Aflatoonianc |Hadi Beitollahie
}

${ }^{a}$ Research Center for Tropical and Infectious Diseases, Kerman University of Medical Sciences, Kerman, Iran

${ }^{b}$ Leishmaniasis Research Center, Kerman University of Medical Sciences, Kerman, Iran

${ }^{c}$ Neuroscience Research Center, Kerman University of Medical Sciences, Kerman, Iran ${ }^{d}$ Esfarayen University of Technology, Esfarayen, Iran

eEnvironment Department, Institute of Science and High Technology and Environmental Sciences, Graduate University of Advanced Technology, Kerman, Iran

\author{
*Corresponding Author: \\ Somayeh Tajik \\ Email: Tajik_s1365@yahoo.com \\ Tel.: +98 (34) 32112794
}

The present study designed an electro-chemical instrument with high sensitivity and selectivity on the basis of a SPE modified with $\mathrm{La}^{+3} / \mathrm{Co}_{3} \mathrm{O}_{4}$ nano-cubes in order to analyze vitamin $\mathrm{B}$. It was confirmed that this sensor possesses very good electronmoderating behaviors to oxidize vitamin $\mathrm{B}_{9}$ in a $0.1 \mathrm{M}$ phosphate buffer solution (PBS) ( $\mathrm{pH}=7.0$ ). In addition, according to optimal conditions ( $\mathrm{pH}=7.0)$, a potential around $110 \mathrm{mV}$ less positive than the one in the un-modified electrodes is required for vitamin B9 oxidation at this electrode surface. This technique limit of determination for vitamin $\mathrm{B}_{9}$ has been estimated to be $0.3 \mu \mathrm{M}(\mathrm{S} / \mathrm{N}=3)$. Responses have been linear in concentrations range between 1.0 and $600.0 \mu \mathrm{M}$. The modified electrode has been applied to detect vitamin $B_{9}$ in real specimens, which was accompanied by acceptable outputs. Experiments showed that $\mathrm{La}^{+3} / \mathrm{Co}_{3} \mathrm{O}_{4}$ nano-cubes will be valuable electrode materials providing a high ratio of surface to volume that enhances sensitivity. The study introduces a novel sensor with simpleness, quickness, sensitivity, and affordability features to quantify vitamin B.

\section{KEYWORDS}

Vitamin $\mathrm{B}_{9}$; $\mathrm{La}^{+3} / \mathrm{Co}_{3} \mathrm{O}_{4}$ nano-cubes; screen printed electrode; modified electrode; voltammetry.

\section{Introduction}

The term "folic" in folic acid (FA) derives from the Latin word folium, meaning leaf, because it was found in the spinach leaf (1941). Moreover, $\mathrm{FA}$ is known as vitamin $\mathrm{B}_{9}$, which makes it a part of vitamin-B complexes. The active form of FA is folate, which exists in food so that human body needs it for its function. FA does not become biologically activated unless it is transformed into an active form of folate [1]. If folic acid introduces into body through certain diets, it generally should be converted to the folate form for effective application. Food folates such as polyglutamates and mono-glutamates (parent compound) are transformed into stomach to dihydrofolate (DHF) and tetrahydrofolate (THF) and afterwards is converted into 5methyl tetrahydrofolate using enzyme 5, 10 methyl-enetetrahydrofolate reductase (MTHFR). The active form of folic acid in plasma is 5-methyl THF [2,3]. This substance contributes to reactions of the single carbon transfer in metabolism, and is the precursor of active tetrahydro folic acid co-enzyme. FA has been explored in spinach for the first time. Its defect leads to the reduced growth in mammalians and various types of anaemia and incapability for making purines and thymine needed to synthesize DNA. Folic acid is one of the potent agents to prevent cancers [4] via scavenging free radicals and antioxidant activities. It consists of the building 
blocks of glutamic acid, p-amino-benzoic acid, and pterin. The superior name for folic acid and its derivatives is folate. Folic acid has been detected by electro-chemical techniques $[5,6]$.

It is clear that the major basis of the electrochemical methods is the analysis of the relationships between detection and current, voltages and resistance. Evolution of novel substances may lead to the building of novel electro-chemical sensors with higher sensitiveness and steadiness $[7,8]$ that have benefits, such as rapid responses, excellent mobility, simple operations, affordability, greater precision, and lower limits of determinations in comparison to the HPLCbased procedures [9-11].

Alternatively, it has been found that nanomaterials features are affected by their sizes and architecture, in particular, because of their surface instead of the nature of bulk atoms [12]. Extreme ratios of surface-tovolume in nano-materials offer these substances a number of benefits, including rapid reaction kinetic, and make them suitable alternatives for single-molecule determinations. Currently, researchers have concentrated on the evaluation of physical, electronic, and chemical properties of nanomaterials for sensor and catalytic uses [13-15].

With regard to the respective electrochemical functions, the materials were employed for modifying the electrode materials. Different fascinating benefits have been also confirmed in bio-science [16]. The existence of nano-particles increases surface areas of the electrode materials and makes easier the electron transfer and rate of reactions $[17,18]$.

SPEs have been proposed in the 1990s for the first time. It has been recognized that these electrodes enjoy more reliable, reproducible, inexpensive, and possible mass manufacturing features [19-21]. They are flexible tools with probable uses in a variety of forms, in which different materials may be applied, and it is possible to simply modify it by various biological specimens, such as enzyme, antibody, synthetic recognition components, and so forth [22-24].

It was demonstrated that higher overpotentials that enhance the background current and largely restrict detection limits are established by direct electro-chemical oxidation of vitamin $\mathrm{B}_{9}$ through an unmodified electrode. Therefore, lanthanides based on the modified electrodes have been designed to determine vitamin $\mathrm{B}_{9}$. As mentioned earlier, the main objective of the present study is to develop a modified electrode to detect vitamin $\mathrm{B}_{9}$ sensitively via $\mathrm{La}^{+3} / \mathrm{Co}_{3} \mathrm{O}_{4}$ nano-cubes for augmenting the SPEs capabilities. The final electrode has been substantially used to determine vitamin $\mathrm{B}_{9}$ in real specimens.

\section{Experimental}

\section{Apparatus and chemicals}

An Autolab potentiostat/galvanostat (PGSTAT 302N, Eco Chemie, the Netherlands) was applied for measuring electrochemicals. General Purpose Electrochemical System (GPES) software was employed to control conditions of experiments. The screen-printed electrode (DropSens, DRP-110, Spain) includes 3 main sections that contain a silver pseudo-reference electrode, a graphite working electrode, and graphite counter electrode. $\mathrm{pH}$ was measured by a Metrohm $710 \mathrm{pH}$ meter.

Vitamin $\mathrm{B}_{9}$ and all the remaining reagents had an analytical grade. They have been prepared via Merck (Darmstadt, Germany). Orthophosphoric acid and the related salts that were above the $\mathrm{pH}$ range of 2.0-9.0 were used for preparing the buffer solutions.

\section{Synthesis of $\mathrm{La}^{+3} / \mathrm{Co}_{3} \mathrm{O}_{4}$ nanocubes}

In a typical synthesis, $25 \mathrm{~mL}$ of ammonia solution (28-30\%, Reagent Chemicals) was first mixed with ultra pure water $(1 / 1, \mathrm{v} / \mathrm{v})$. Then, $0.05 \mathrm{~g}$ of poly(vinylpyrrolidone) (PVP; 
M.W. 58,000, Reagent Chemicals) was dissolved in the solution. After shaking for a few minutes, $0.364 \mathrm{~g}$ of cobalt nitrate hexahydrate $\left(\mathrm{Co}\left(\mathrm{NO}_{3}\right)_{2} \cdot 6 \mathrm{H}_{2} \mathrm{O}\right)$ and $0.043 \mathrm{~g}$ of lanthanum nitrate hexahydrate $\left(\mathrm{La}\left(\mathrm{NO}_{3}\right)_{2} \cdot 6 \mathrm{H}_{2} \mathrm{O}\right)$ were added into the reaction medium. After sonication, a browny transparent solution was obtained, which was then transferred into a $100 \mathrm{~mL}$ Teflon-lined stainless steel autoclave. The autoclave was kept in an electric oven at $180{ }^{\circ} \mathrm{C}$ for $6 \mathrm{~h}$, after which the autoclave was taken out and cooled naturally to room temperature. After that, the black precipitate was harvested and washed with ultra-pure water several times via centrifugation. The product was then dried at $60{ }^{\circ} \mathrm{C}$ overnight, before being calcined at 300 ${ }^{\circ} \mathrm{C}$ for $2 \mathrm{~h}$ in air to be converted into $\mathrm{La}^{3+} / \mathrm{Co}_{3} \mathrm{O}_{4}$ nanocubes.

\section{Preparation of the electrode}

As seen below, $\mathrm{La}^{3+} / \mathrm{Co}_{3} \mathrm{O}_{4}$ nanocubes was applied to coat the bare screen printed electrode. Dispersion of $1 \mathrm{mg}$ of $\mathrm{La}^{3+} / \mathrm{Co}_{3} \mathrm{O}_{4}$ nanocubes with ultrasonication for $1 \mathrm{~h}$ was used for preparing a stock solution of $\mathrm{La}^{3+} / \mathrm{Co}_{3} \mathrm{O}_{4}$ nanocubes in $1 \mathrm{~mL}$ of the aqueous solution, whereas $2 \mu \mathrm{l}$ of aliquots of the $\mathrm{La}^{3+} / \mathrm{Co}_{3} \mathrm{O}_{4} / \mathrm{H}_{2} \mathrm{O}$ suspension solution was cast on the carbon working electrodes. Then, it remained up to the time of evaporation of the solvent in room temperature.

\section{Preparation of real samples}

Samples of urine have been kept in a refrigerator directly after gathering. Ten millilitres of samples have been centrifuged for fifteen minutes at 2,000 rpm. The supernatant has been filtered by a $0.45 \mu \mathrm{m}$ filter. Next, various volumes of solution has been transported into a 25 millilitres volumetric flask and diluted to the mark with PBS $(\mathrm{pH}=7.0)$. This diluted urine samples were anaesthetized with different amounts of vitamin $\mathrm{B}_{9}$. Content of vitamin $\mathrm{B}_{9}$ have been analyzed by the suggested procedure by employing the standard addition method.

Five vitamin $\mathrm{B}_{9}$ pill (with the labling 100 mg per tablet, Tehran Chemie Pharmaceutical Co., Iran) have been ground. Afterwards, the pill solution has been prepared via dissolving $500 \mathrm{mg}$ of powder in $25 \mathrm{~mL}$ water through ultra-sonication. Next, various volumes of the diluted solution has been transported in a 25 $\mathrm{mL}$ volumetric flask and diluted to the mark with $\mathrm{PBS}(\mathrm{pH}=7.0)$. The vitamin $\mathrm{B}_{9}$ contents have been analyzed by the recommended technique via the standard addition method.

\section{Result and discussion}

\section{Nanostructures characterization}

Figure 1 displays the Fourier Transform Infrared (FT-IR) spectra of $\mathrm{La}^{3+} / \mathrm{Co}_{3} \mathrm{O}_{4}$ nanocubes sample in the frequency range of 400-4000 $\mathrm{cm}^{-1}$. The Fourier Transform Infrared spectrum of $\mathrm{La}^{3+} / \mathrm{Co}_{3} \mathrm{O}_{4}$ nanocubes showed strong vibrational bands in the lower frequency regions (about 400-600 $\mathrm{cm}^{-1}$ ), ascribable to the vibration of metal-0. The absorption seen at $\sim 3389 \mathrm{~cm}^{-1}$ is thought to be due to the symmetric vibration of the $-\mathrm{OH}$ groups of the absorbed $\mathrm{H}_{2} \mathrm{O}$ molecules. The peak at $\sim 1632 \mathrm{~cm}^{-1}$ corresponds to $\mathrm{O}-\mathrm{H}$ groups, again related to adsorbed $\mathrm{H}_{2} \mathrm{O}$ molecules [25].

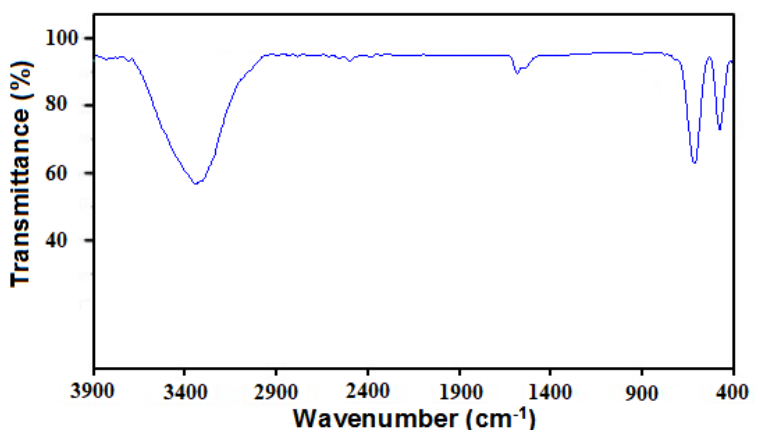

FIGURE 1 Fourier-transform infrared spectroscopy (FTIR) image of La3+/Co304 nanocubes

The main characteristic diffraction peaks of the $\mathrm{La}^{3+} / \mathrm{Co}_{3} \mathrm{O}_{4}$ nanocubes are consistent with 
the standard patterns of $\mathrm{Co}_{3} \mathrm{O}_{4}$ (JCPDS card No. 71-0816) with cubic spinel phase, suggesting that the doping of La will not change the backbone of pristine $\mathrm{Co}_{3} \mathrm{O}_{4}$ (Figure 2). As increase of $\mathrm{La}$ in the $\mathrm{Co}_{3} \mathrm{O}_{4}$, the characteristic peak at $2 \theta=37.3^{\circ}$ become weaker and slightly shift to small-angle reflections with increase of $\mathrm{La}$ in the $\mathrm{Co}_{3} \mathrm{O}_{4}$. The introduction of the La ions with $\mathrm{f}$ electronic and large atomic radiuses into the $\mathrm{Co}_{3} \mathrm{O}_{4}$ grain boundary causes the loss of atoms degree of order of $\mathrm{Co}_{3} \mathrm{O}_{4}$, thereby contributing to the limited growth of the grain, grain refinement and the decrease of crystallinity [26].

The broadness of the diffraction peaks suggests the nano-sized nature of the product and the average crystallite size $(\mathrm{t})$ of it was calculated using the Debye-Scherrer formula as $67.0 \mathrm{~nm}$. $\mathrm{t}=0.9 \lambda / \beta \cos (\theta)$ where $\lambda$ is the wavelength of the X-ray radiation $(1.54056 \AA$ for $C u$ lamp), $\theta$ is the diffraction angle and $\beta$ is the full width at half-maximum (FWHM).

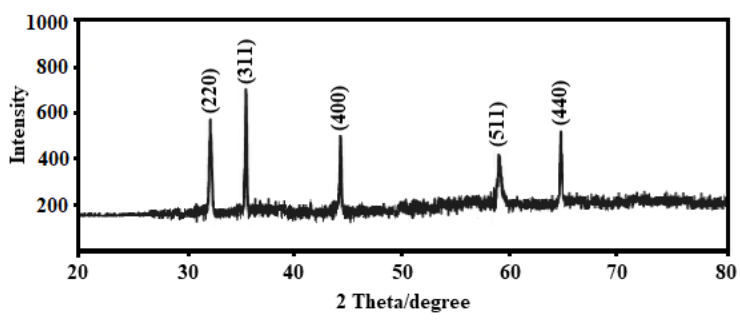

FIGURE 2 X-ray diffraction (XRD) pattern of $\mathrm{La}^{3+} / \mathrm{Co}_{3} \mathrm{O}_{4}$ nanocubes

The morphology of the product was examined by scanning electron microscope (SEM). Figure 3 depicts the scanning electron microscope pictures of $\mathrm{La}^{3+} / \mathrm{Co}_{3} \mathrm{O}_{4}$ nanoparticles. From the graph, it was observed that the nanoparticles, are nanocubes and they are seen as less than 70 $\mathrm{nm}$.

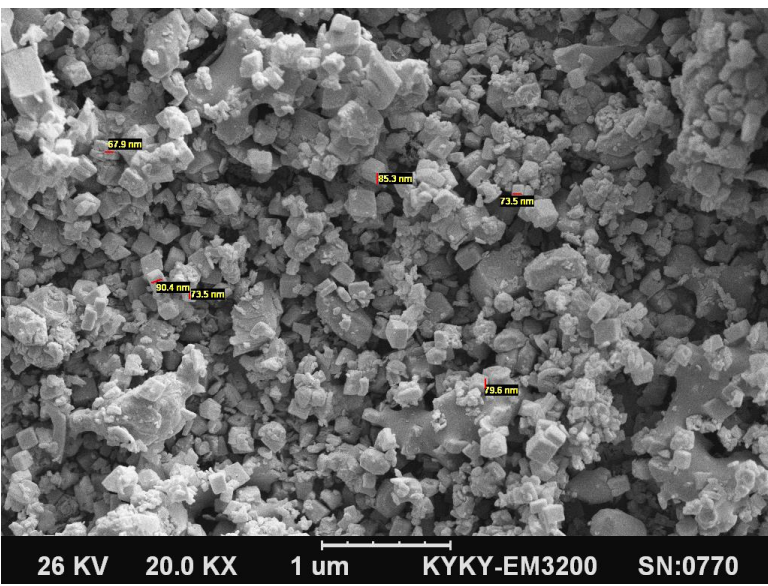

FIGURE 3 Scanning electron microscopic (SEM) image of $\mathrm{La}^{3+}$-doped $\mathrm{Co}_{3} \mathrm{O}_{4}$ nanocubes

\section{Electrochemical behaviour of vitamin $B_{9}$ at the surface of various electrodes}

The electrochemical behaviour of vitamin $\mathrm{B}_{9}$ depends on the $\mathrm{pH}$ value of the aqueous solution (Figure 4). Thus, it is essential to optimize the solution $\mathrm{pH}$ in order to gain more useful results for electro-oxidation of vitamin B9. Therefore, vitamin $B_{9}$ electrochemical behaviour was examined in $0.1 \mathrm{M}$ PBS at distinct $\mathrm{pH}$ numbers (2.0-9.0) at $\mathrm{La}^{3+} / \mathrm{Co}_{3} \mathrm{O}_{4}$ /SPE surface by voltammetry. The results indicated more advantageousness of neutral conditions for vitamin $\mathrm{B}_{9}$ electro-oxidation at $\mathrm{La}^{3+} / \mathrm{Co}_{3} \mathrm{O}_{4} / \mathrm{SPE}$ surface in comparison to the basic or acidic medium, because the obtained current was more than other pHs. Here, pH 7.0 was selected as an optimal $\mathrm{pH}$ for vitamin $\mathrm{B}_{9}$ electro-oxidation at $\mathrm{La}^{3+} / \mathrm{Co}_{3} \mathrm{O}_{4} / \mathrm{SPE}$ surface. 
<smiles>CCCCCCC(NC(=O)c1ccc(NCc2cnc3nc(N)[nH]c(=O)c3n2)cc1)C(=O)O</smiles><smiles>Nc1nc2ncc(/C=N/c3ccc(C(=O)NC(CCC(=O)O)C(=O)O)cc3)nc2c(=O)[nH]1</smiles>

FIGURE 4 Electrochemical oxidation of vitamin $\mathrm{B}_{9}$

Figure 5 shows responses of CV to electrooxidation of $100.0 \mu \mathrm{M}$ vitamin $\mathrm{B}_{9}$ at the unmodified SPE (curve b) and $\mathrm{La}^{3+} / \mathrm{Co}_{3} \mathrm{O}_{4} / \mathrm{SPE}$ (curve a). The peak potential occurs at $620 \mathrm{mV}$ due to vitamin $\mathrm{B}_{9}$ oxidation, which is around $110 \mathrm{mV}$ more negative than the unchanged SPE. Furthermore, $\mathrm{La}^{3+} / \mathrm{Co}_{3} \mathrm{O}_{4} / \mathrm{SPE}$ exhibits very high anodic peak currents for vitamin $\mathrm{B}_{9}$ oxidation than that of the unchanged SPE. This showed a significant improvement of the electrode performance toward vitamin $\mathrm{B}_{9}$ oxidation by changing the constant SPE with $\mathrm{La}^{3+} / \mathrm{Co}_{3} \mathrm{O}_{4}$ nanocubes.

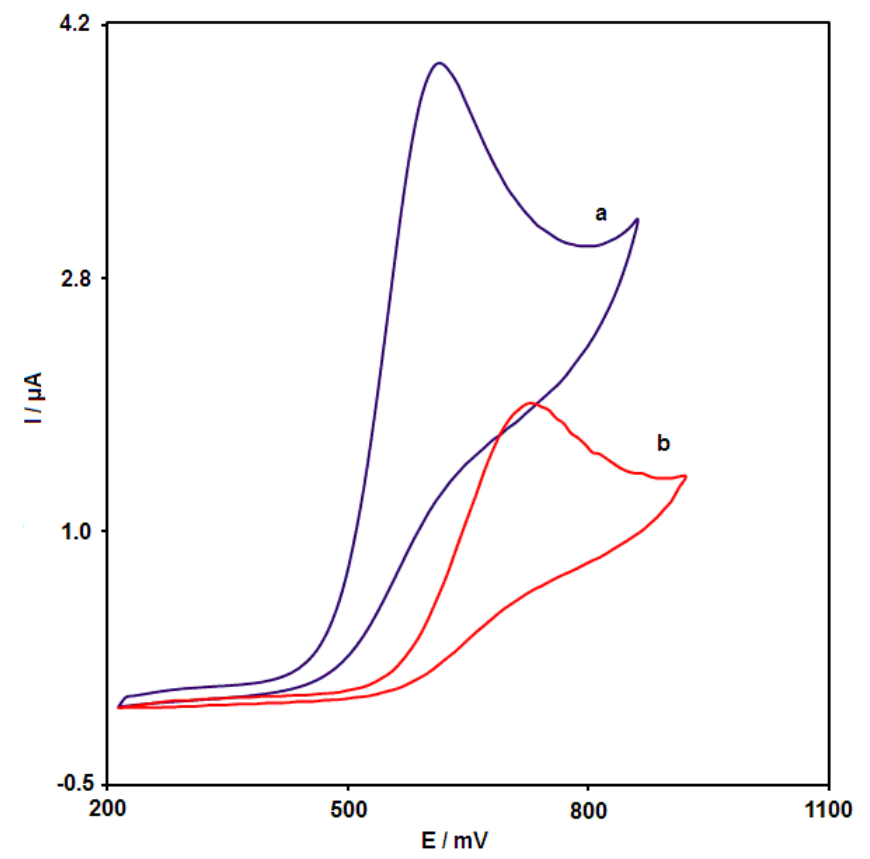

FIGURE 5 CVs of a) $\mathrm{La}^{+3} / \mathrm{Co}_{3} \mathrm{O}_{4}$ nanocubes /SPE and b) unmodified SPE in the presence of 100.0 $\mu \mathrm{M}$ of vitamin $\mathrm{B}_{9}$ at $\mathrm{pH}$ 7.0. In all cases, the scan rate was $50 \mathrm{mV} \mathrm{s}^{-1}$ 


\section{Effect of scan rate}

Researchers investigated the impact of the rates of potential scan on vitamin $\mathrm{B}_{9}$ oxidation current (Figure 6). Findings indicated induction of enhancement in the current of the peak by the increased potential scan rate. Additionally, diffusion in oxidation process is monitored, as inferred by the linear dependence of the anodic peak current (Ip) on the square root of the potential scan rate $\left(v^{1 / 2}\right)$ for vitamin $\mathrm{B}_{9}$ (Figure 6A) [27].

Data of the ascending section of the current-voltage curve, which has been registered at a scan rate of $10 \mathrm{mVs}^{-1}$ for vitamin $\mathrm{B}_{9}$, was used for drawing Tafel plot (Figure 6B). Electron transfer kinetics between $\mathrm{La}^{3+} / \mathrm{Co}_{3} \mathrm{O}_{4}$ /SPE and substrate (vitamin $\mathrm{B}_{9}$ ) affect these sections of voltammogram that are called Tafel region. The study achieved Tafel slope of $0.1194 \mathrm{mV}$. This finding is compatible with the engagement of one electron at the rate that determines the electrode process phase [27], providing that charge transfer coefficients $\alpha=$ 0.5 for vitamin $\mathrm{B}_{9}$.

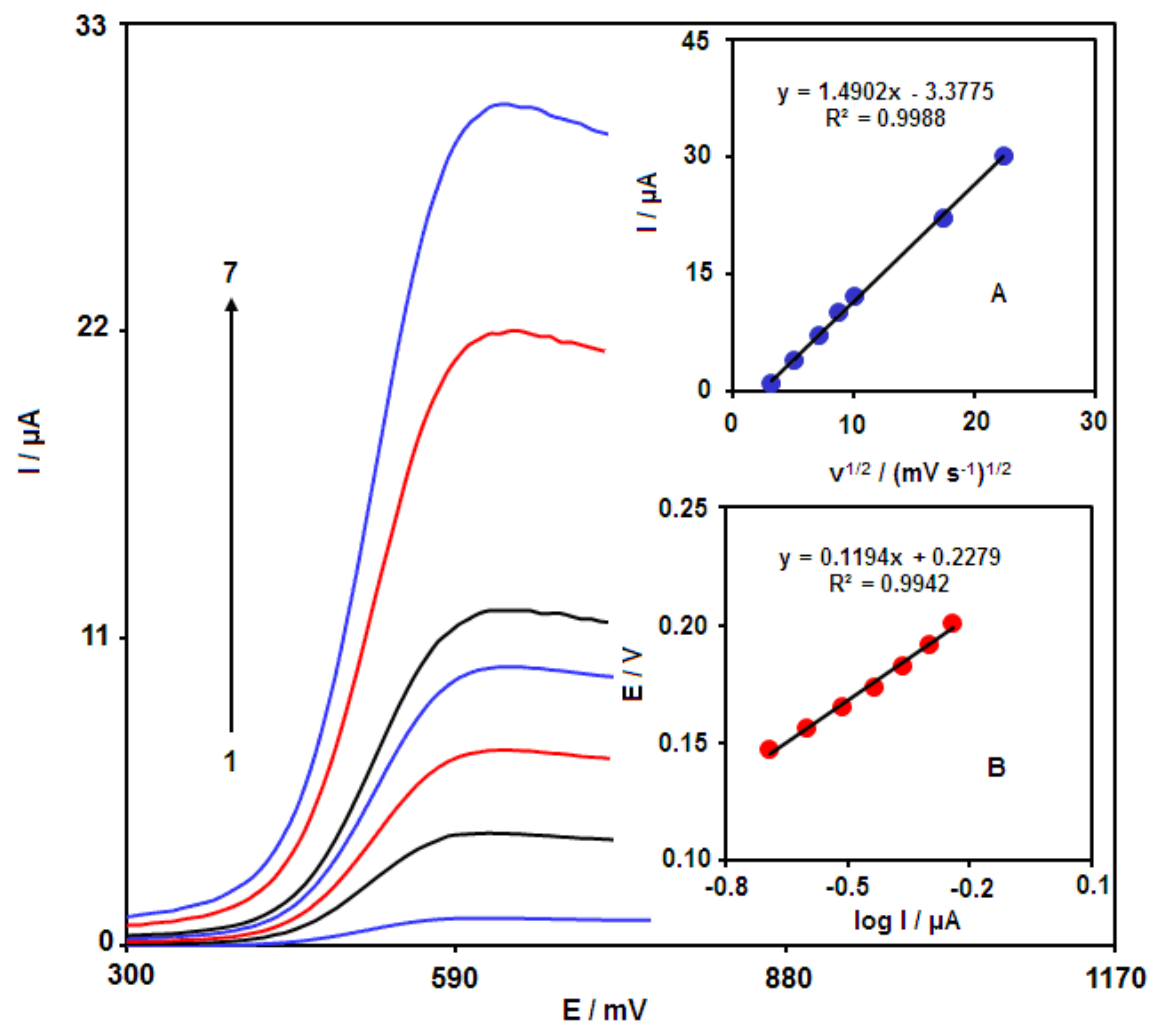

FIGURE 6 LSVs of $\mathrm{La}^{+3} / \mathrm{Co}_{3} \mathrm{O}_{4}$ nanocubes /SPE in 0.1 M PBS (pH 7.0) containing $200.0 \mu \mathrm{M}$ of vitamin $B_{9}$ at various scan rates; numbers $1-7$ correspond to $10,25,50,75,100,300$ and $500 \mathrm{mV}$ $\mathrm{s}^{-1}$, respectively. Inset: (A) Variation of anodic peak current vs. square root of scan rate. (B) Variation anodic peak potential vs. $\log v$

\section{Chronoamperometric measurements}

Chronoamperometric measurements of vitamin $\mathrm{B}_{9}$ at $\mathrm{La}^{3+} / \mathrm{Co}_{3} \mathrm{O}_{4} / \mathrm{SPE}$ were conducted by adjusting the working electrode potential at $670 \mathrm{mV}$ for different concentrations of vitamin $\mathrm{B}_{9}$ (Figure 7) in PBS (pH 7.0). For electroactive materials (vitamin $\mathrm{B}_{9}$ in this case) with a diffusion coefficient of $\mathrm{D}$, the Cottrell equation describes current seen for electrochemical reaction at the mass transport limited condition [27]:

$$
\mathrm{I}=\mathrm{nFAD}^{1 / 2} \mathrm{C}_{\mathrm{b}} \pi^{-1 / 2} \mathrm{t}^{-1 / 2}
$$

where $\mathrm{D}$ and $\mathrm{C}_{\mathrm{b}}$ respectively represent diffusion coefficient $\left(\mathrm{cm}^{2} \mathrm{~s}^{-1}\right)$ and bulk 
concentration $\left(\mathrm{mol} \mathrm{cm}^{-3}\right)$. Experimental plots of I versus $t^{-1 / 2}$ were used with the best fits for various concentrations of vitamin $\mathrm{B}_{9}$ (Figure 7A). Then, the resultant straight lines slopes were drawn against vitamin $\mathrm{B}_{9}$ concentrations
(Figure 7B). According to the resultant slope and the Cottrell equation, mean values of $\mathrm{D}$ were $2.75 \times 10^{-5} \mathrm{~cm}^{2} / \mathrm{s}$ for vitamin $\mathrm{B}_{9}$. This value is comparable with some previous reports $\left(9.749 \times 10^{-5} \mathrm{~cm}^{2} / \mathrm{s}\right.$ [28]).

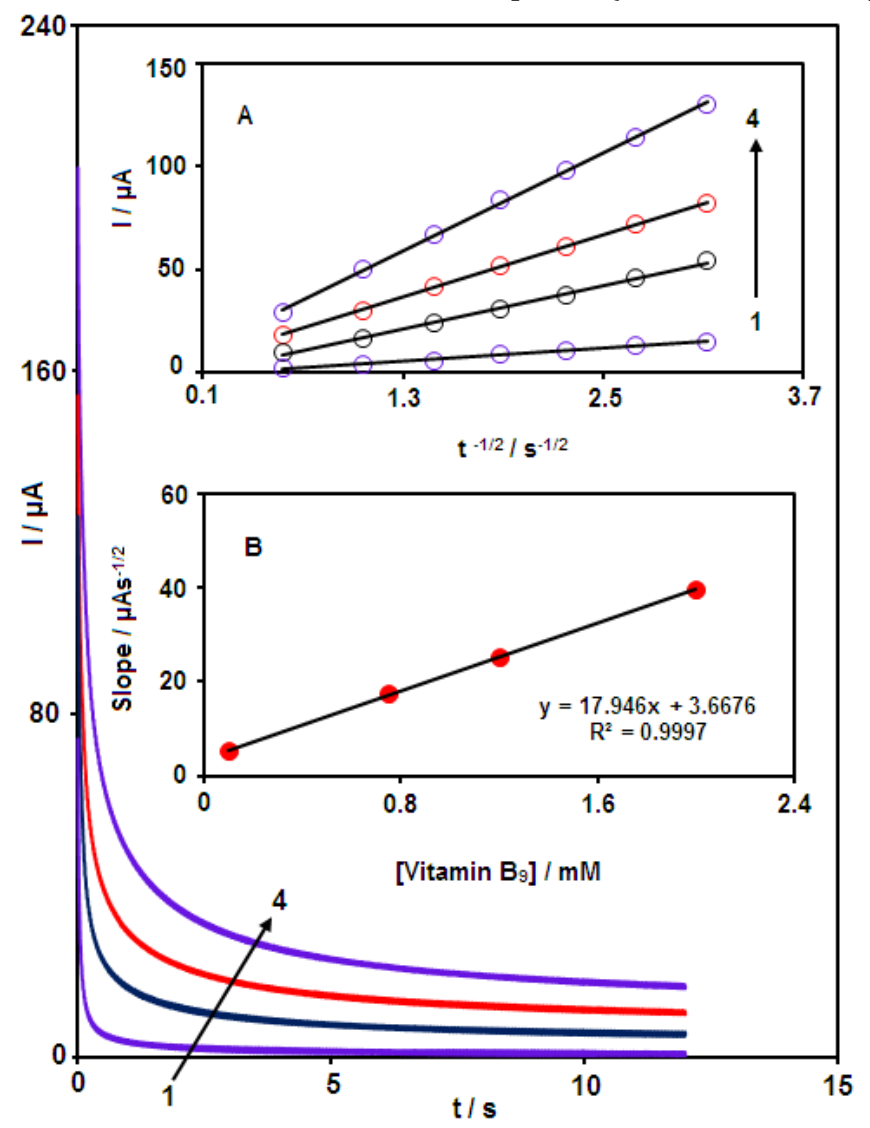

FIGURE 7 Chronoamperograms obtained at $\mathrm{La}^{+3} / \mathrm{Co}_{3} \mathrm{O}_{4}$ nanocubes/SPE in $0.1 \mathrm{M}$ PBS (pH 7.0) for different concentrations of vitamin $B_{9}$. The numbers 1-4 correspond to $0.1,0.75,1.2$ and $2.0 \mathrm{mM}$ of vitamin B9. Insets: (A) Plots of I vs. $\mathrm{t}^{-1 / 2}$ obtained from chronoamperograms 1-4. (B) Plot of the slope of the straight lines against vitamin $\mathrm{B}_{9}$ concentrations

\section{Calibration plot and limit of detection}

The electro-peak currents of vitamin $\mathrm{B}_{9}$ at $\mathrm{La}^{3+} / \mathrm{Co}_{3} \mathrm{O}_{4} / \mathrm{SPE}$ surface can be applied to define vitamin $\mathrm{B}_{9}$ in thoxidation e solution. Since the increased sensitivity and more suitable properties for analytical utilizations are considered as the benefits of differential pulse voltammetry (DPV), $\mathrm{La}^{3+} / \mathrm{Co}_{3} \mathrm{O}_{4} / \mathrm{SPE}$ in $0.1 \mathrm{M}$ PBS consisting of different distinct concentrations of vitamin $\mathrm{B}_{9}$ was used to conduct DPV experiments (Figure 8) (Initial potential $=440 \mathrm{mV}$, End potential $=700 \mathrm{mV}$, Step potential $=0.01 \mathrm{~V}$ and pulse amplitude $=0.025 \mathrm{~V}$ ). It was found that the electrocatalytic peak currents of vitamin $\mathrm{B}_{9}$ oxidation at $\mathrm{La}^{3+} / \mathrm{Co}_{3} \mathrm{O}_{4} / \mathrm{SPE}$ surface linearly depended on vitamin $\mathrm{B}_{9}$ concentrations above the range of 1.0-600.0 $\mu \mathrm{M}$ (with a correlation coefficient of 0.9993), while determination limit $(3 \sigma)$ was achieved to be $0.3 \mu \mathrm{M}$. These values are comparable with the values obtained by other researchers (Table 1 ). 


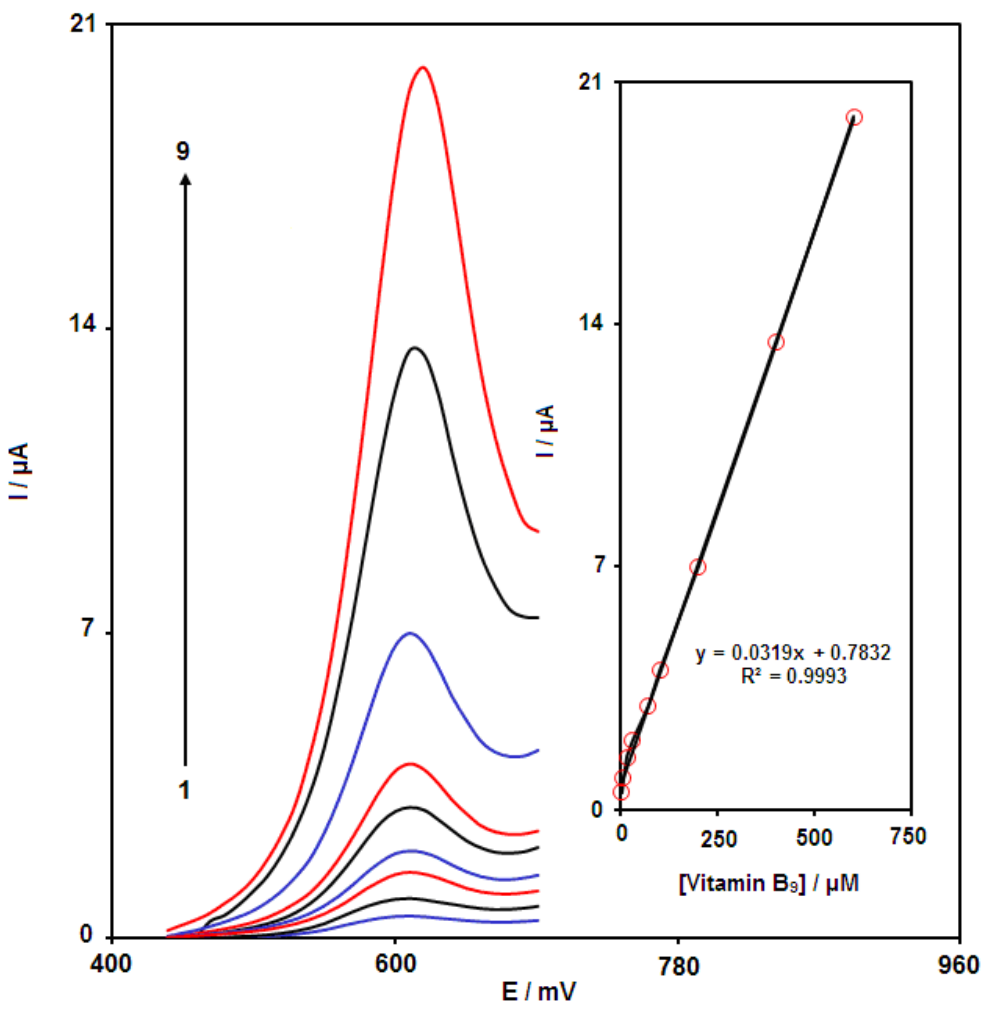

FIGURE 8 DPVs of $\mathrm{La}^{+3} / \mathrm{Co}_{3} \mathrm{O}_{4}$ nanocubes /SPE in $0.1 \mathrm{M}$ PBS (pH 7.0) containing different concentrations of vitamin $B_{9}$. Numbers $1-9$ correspond to 1.0, 5.0, 15.0, 30.0, 70.0, 100.0, 200.0, 400.0 and $600.0 \mu \mathrm{M}$ of vitamin $\mathrm{B}_{9}$. The inset shows the plot of the peak current as a function of the vitamin $\mathrm{B}_{9}$ concentration in the range of 1.0-600.0 $\mu \mathrm{M}$

TABLE 1 Comparison of the efficiency of some modified electrodes used in detection of vitamin $\mathrm{B}_{9}$

\begin{tabular}{|c|c|c|c|c|c|}
\hline Method & Electrode & Modifier & $\begin{array}{c}\text { Linear } \\
\text { range }(\mu \mathrm{M})\end{array}$ & $\begin{array}{r}\text { Detection } \\
\text { limit }(\mu \mathrm{M})\end{array}$ & Ref \\
\hline Voltammetry & Glassy carbon & MWCNT & $0.3-80.0$ & 0.13 & [28] \\
\hline Voltammetry & Carbon paste & MWCNT & $4.6-152.0$ & 1.1 & [29] \\
\hline Voltammetry & Carbon paste & $\begin{array}{l}\text { (DEDE) and NiO/CNTs } \\
\text { nanocomposite } \\
\text { Ruthenium(II) }\end{array}$ & $3.0-550.0$ & 0.9 & [30] \\
\hline Voltammetry & Carbon paste & $\begin{array}{l}\text { Complex-ZnO/CNTs } \\
\text { Nanocomposite }\end{array}$ & $3.0-700.0$ & 1.0 & {$[31]$} \\
\hline Voltammetry & Carbon paste & $\mathrm{ZrO}_{2}$ nanoparticles & $20.0-2500.0$ & 9.86 & {$[32]$} \\
\hline Voltammetry & Screen printed & $\mathrm{La}^{+3} / \mathrm{Co}_{3} \mathrm{O}_{4}$ & $1.0-600.0$ & 0.3 & $\begin{array}{l}\text { This } \\
\text { work }\end{array}$ \\
\hline
\end{tabular}


TABLE 2 Determination of vitamin $B_{9}$ in real samples. All the concentrations are in $\mu M(n=5)$

\begin{tabular}{lllll}
\hline Sample & Spiked & Found & Recovery (\%) & R.S.D. (\%) \\
\hline \multirow{4}{*}{ Urine } & 0 & - & - & - \\
& 5.0 & 4.9 & 98.0 & 3.2 \\
& 10.0 & 10.3 & 103.0 & 2.1 \\
& 15.0 & 15.3 & 102.0 & 1.9 \\
& 20.0 & 19.9 & 99.5 & 2.8 \\
Tablet & 0 & 7.0 & - & 2.7 \\
& 2.5 & 9.3 & 97.9 & 1.9 \\
& 7.5 & 15.0 & 103.4 & 3.4 \\
& 12.5 & 19.8 & 101.5 & 2.4 \\
\hline
\end{tabular}

\section{Real sample analysis}

The method illustrated above was used to evaluate $\mathrm{La}^{3+} / \mathrm{Co}_{3} \mathrm{O}_{4}$ /SPE usability for determining vitamin $\mathrm{B}_{9}$ in real samples in order to determine vitamin $\mathrm{B}_{9}$ in tablet and urine samples. Therefore, the standard addition technique was applied. Table 2 reports the results. Acceptable recoveries of vitamin $\mathrm{B}_{9}$ were observed, and reproducible results were shown with regard to the mean relative standard deviation (R.S.D.).

\section{The repeatability and stability of $\mathrm{La}^{3+} / \mathrm{Co}_{3} \mathrm{O}_{4}$ nanocubes /SPE}

The long-term stability of the $\mathrm{La}^{3+} / \mathrm{Co}_{3} \mathrm{O}_{4}$ nanocubes /SPE was tested over a 3-week period. When CVs were recorded after the modified electrode was stored in an atmosphere at room temperature, the peak potential for vitamin $\mathrm{B}_{9}$ oxidation was unchanged and the current signals showed only less than $2.2 \%$ decrease of the initial response. The antifouling properties of modified electrode towards vitamin $\mathrm{B}_{9}$ oxidation and its oxidation products were investigated by recording the cyclic voltammograms of modified electrode before and after using in the presence of vitamin $\mathrm{B}_{9}$. Cyclic voltammograms were recorded in the presence of vitamin $\mathrm{B}_{9}$ after having cycled the potential for 15 cycles at a scan rate $50 \mathrm{mV} \mathrm{s}^{-1}$. The peak potentials were unchanged to positive values and the currents decreased by less than $2.3 \%$. Therefore, at the surface of $\mathrm{La}^{3+} / \mathrm{Co}_{3} \mathrm{O}_{4}$ nanocubes /SPE, not only the sensitivity increases, but the fouling effect of the analyte and its oxidation product also decreases.

\section{Conclusion}

This study aimed to develop the screenprinted electrode modified with $\mathrm{La}^{+3} / \mathrm{Co}_{3} \mathrm{O}_{4}$ nano-cubes and use it as a new sensor for detecting vitamin $\mathrm{B}_{9}$ with higher sensitivity and selectivity. Findings showed the designed instrument functions with features of portability, affordability, and disposability to determine vitamin $\mathrm{B}_{9}$. Moreover, limit of detection for vitamin $\mathrm{B}_{9}$ has been estimated as $0.3 \mu \mathrm{M}$. In general, it has been viewed a very good device for analytic procedures in the clinic where determining the levels of traces of vitamin $\mathrm{B}_{9}$ will be necessary.

\section{Acknowledgements}

The authors acknowledge the financial support provided for this project (Project No. 97000583 and ethics code (IR.KMU.REC.1397.270) by the Neuroscience Research Center, Kerman University of Medical Sciences, Kerman, Iran.

\section{Orcid:}

Somayeh Tajik: https://orcid.org/0000-00021151-5515 


\section{References}

[1] M. Kuceki, F.M. de Oliveira, M. Gava Segatelli, M.K. Lombello Coelho, A. César Pereira, L. Rianne da Rocha, J. de Cássia Mendonça, C.R. Teixeira Tarley, J. Electroanal. Chem., 2018, 818, 223-230.

[2] C.M. Kuskur, B.E.K. Swamy, H. Jayadevappa, Anal. Bioanal. Electrochem., 2018, 10, 658674.

[3] E.J.T. McGee, A.R. Sangakkara, L.L. Diosady, J. Food Eng., 2017, 198, 72-80.

[4] W. Shi, Y. Wang, H. Zhang, Z. Liu, Z. Fei, Food Chem., 2017, 226, 128-134.

[5] M. Czarnowska-Kujawska, E. Gujska, J. Michalak, J. Food Compos. Anal., 2017, 57, 6472.

[6] A. Taherkhani, T. Jamali, H. Hadadzadeh, H. Karimi-Maleh, H. Beitollahi, M. Taghavi, F. Karimi, Ionics, 2014, 20, 421-429.

[7] A.R. Taheri, A. Mohadesi, D. Afzali, H. Karimi-Maleh, H. Mahmudi moghaddam, H. Zamani, Z. Rezayati zad, int. J. Electrochem. Sci., 2011, 6, 171-180.

[8] M.R. Ganjali, Z. Dourandish, H. Beitollahi, S. Tajik, L. Hajiaghababaei, B. Larijani, Int. J. Electrochem. Sci, 2018, 13, 2448-2461.

[9] A. Babaei, M. Aminikhah, A. Taheri, Sensor Letters, 2013, 11, 413-422.

[10] S.E. Baghbamidi, H. Beitollahi, S. Tajik, R. Hosseinzadeh, Int. J. Electrochem. Sci., 2016, 11, 10874-10883.

[11] Z.R. Zad, S.S.H. Davarani, A. Taheri, Y. Bide, Journal of Molecular Liquids, 2018, 253, 233-240.

[12] D. Zhang, L. Li, W. Ma, X. Chen, Y. Zhang, Mater. Sci. Eng. C, 2017, 70, 241-249.

[13] D.B. Gorle, M.A. Kulandainathan, RSC Adv., 2016, 6, 19982-19991.

[14] D.D. Ramteke, H.C. Swart, R.S. Gedam, J. Rare Earth., 2017, 35, 480-484.

[15] N.S. Ramgir, Y. Yang, M. Zacharias, Small, 2010, 6, 1705-1722.

[16] H. Beitollahi, S. Tajik, M.H. Asadi, P. Biparva, J. Anal. Sci. Tech., 2014, 5, 29-37.
[17] M. Mazloum-Ardakani, H. Beitollahi, M.K. Amini, F. Mirkhalaf, B.F. Mirjalili, A. Akbari, Analyst, 2011, 136, 1965-1970.

[18] G.G. Gerent, A. Spinelli, J. Hazard. Mater., 2017, 330, 105-115.

[19] F. Arduini, L. Micheli, D. Moscone, G. Palleschi, S. Piermarini, F. Ricci, G. Volpe, TrACTrend. Anal. Chem., 2016, 79, 114-126.

[20] D. Martín-Yerga, E. Costa Rama, A. Costa García, J. Chem. Educ. 2016, 93, 1270-1276.

[21] L.M. Ochiai, D. Agustini, L.C. FigueiredoFilho, C.E. Banks, L.H. Marcolino-Junior, M.F. Bergamini, Sens. Actuators B-Chem., 2017, 241, 978-984.

[22] H. Beitollahi, Z. Dourandish, S. Tajik, M.R. Ganjali, P. Norouzi, F. Faridbod, J. Rare Earths, 2018, 36, 750-757.

[23] K.J. Grennan, A.R. Killard, M. Smyth, Electroanalysis, 2001, 13, 745-750.

[24] F. Tan, L. Cong, X. Li, Q. Zhao, H. Zhao, X. Quan, J. Chen, Sens. Actuators-B Chem. 2016, 233, 599-606.

[25] B.M. Abu-Zied, S.M. Bawaked, S.A. Kosa, W. Schwieger, J. Nanomater., 2015, 16, 432.

[26] J. Xu, F. Huo, Y. Zhao, Y. Liu, Q. Yang, Y. Cheng, S. Min, Z. Jin, Z. Xiang, Int. J. Hydrog. Energy, 2018, 43, 8674-8682.

[27] A. Bard, L. Faulkner, second ed., New York: Wiley, 2001.

[28] X.L. Jiang, R. Li, J. Li, X. He, Russ. J. Electrochem., 2009, 45, 772-777.

[29] A.A. Ensafi, H. Karimi-Maleh, J. Electroanal. Chem., 2010, 640, 75-83.

[30] H. Karimi-Maleh, P. Biparva, M. Hatami, Biosens. Bioelectron, 2013, 48, 270-275.

[31] H. Karimi-Maleh, F. Tahernejad-Javazmi, M. Daryanavard, H. Hadadzadeh, A.A. Ensafi, M. Abbasghorbani, Electroanalysis, 2014, 26, 962-970.

[32] M. Mazloum-Ardakani, H. Beitollahi, M.K. Amini, F. Mirkhalaf, M. Abdollahi-Alibeik, Sens. Actuators B Chem., 2010, 151, 243-249.

How to cite this article: Mohammad Reza Aflatoonian, Somayeh Tajik*, Mehri-Saddat Ekrami-Kakhki, Behnaz Aflatoonian, Hadi Beitollahi, A nano-sensor based on screen printed electrode (SPE) for electro-chemical detection of vitamin B $_{9}$. Eurasian Chemical Communications, 2020, 2(5), 609-618. Link: http://www.echemcom.com/article_102528. 